primigravide) one wonders how your contributors define toxaemia.

There are several non sequiturs in the text which others among your readers will doubtless wish to question. I would only ask why, when they show themselves to be so progressive in their approach to the active management of labour, your contributors are so adamantly retrogressive in their attitude towards the management of pain in labour? -I am, etc.,

J. Selwyn Crawford

Birmingham Maternity Hospital,

Birmingham

1 Crawford, J. S., Principles and Practice of $\mathrm{Ob}$ stetric Anaesthesia, 3rd edn. Oxford, Blackwell, 1972.

2 Pearson, J. F., in Proceedings of Symposium on Epidural Analgesia in Obstetrics, ed. A. 3 Crawford, J. S. S., Davies, P., and Pearson, J. F., British łournal of Anaesthesia, 1973, 45, 148.

\section{Intensive Care in a District General Hospital}

SiR,-The article by Dr. A. R. Tanser and Mr. B. G. Wetton (28 July, p. 227) on their experience with a multipurpose intensive care unit underlines not only the quality of care that it is now possible to provide in a district general hospital but also the stimulating effect that such a unit has on the nursing and medical care in the rest of the hospital.

A similar four-bedded unit has now been running at Kettering General Hospital since 1963, and our experience with such a unit was described after two years. ${ }^{1}$ The admission rate has risen steadily from 217 in 1963 to 503 in 1972, the average length of stay having been reduced from 4 days 21 hours to 2 days 8 hours (56 hours)-very similar to the average length of stay (57 hours) in the unit at the St. Martin's Hospital, Bath, as reported by Dr. Tanser and Mr. Wetton. Another remarkable similarity is their finding that $62 \%$ admissions are for "Medical" conditions, our corresponding figure in 1971 being $63 \%$. There is such remarkable correspondence between the percentage of total admissions for different conditions in the two units that it seems worth while to record them:

\begin{tabular}{l|c|c}
\hline & $\begin{array}{c}\text { Bath, } \\
1968-71\end{array}$ & $\begin{array}{c}\text { Kettering } \\
1972\end{array}$ \\
\hline Myocardial infarction & 31.1 & 30.2 \\
Other cardiac disorders & 6.4 & Not available \\
Self-poisoning & 13.3 & 16.1 \\
Respiratory disorders & 12.4 & Not available \\
Surgical & 11.1 & 9.3 \\
Trauma & 10.3 & 14.1 \\
Others & 15.4 & 9.9 \\
\hline
\end{tabular}

It would seem, therefore, that those thinking of setting up such multipurpose units in district general hospitals could take these figures as a fair prediction of the cases they will admit in the course of a year, and plan accordingly.

From our system of recording each admission to the unit, which is separate from the usual hospital records, we have determined that $22 \%$ of patients are unconscious on admission and that $8.5 \%$ are admitted as a result of road traffic accidents. The overall mortality is $15 \%$. One in 20 of all hospital admissions pass through the intensive care unit. The cost of each patient's stay is $£ 60$, a small price to pay for a life, for if admitted to any other ward they would almost certainly die. Of this $£ 60$, the majority of the cost is in nurses' salaries-£46; 112 goes for drugs and dressings and the remaining £2 for heating, lighting, and food. Nothing extra is allowed for doctors' salaries, which would be the same were there no intensive care unit.

I hope there are few district general hospitals in the United Kingdom without such a unit. If there are, I would strongly urge them to get on with building one on the lines of the unit at Bath. The impetus to build the unit must come from the medical staff, and some enthusiast must be found to be in administrative charge; "for nothing great was ever achieved without enthusiasm" (Emmerson $\left.{ }^{2}\right)$.- I am, etc.,

Department of Medicine,

Kettering and District General Hospital
Kettering, Northants

Crockett, G. S., and Barr, A., British Medical Fournal, 1965, 2, 1173 Macmillan, 1883. Essays, ed. J. Morley. London,
Marson, R. W,

\section{Radiological Evaluation of Pulmonary} Metastases

SIR,-In the report by the Clinical Screening Group of the European Organization for Research on the Treatment of Cancer (28 July, p. 199) two chest radiographs were reproduced (fig. 3) purporting to show complete regression of a pulmonary metastasis from a renal carcinoma.

It is our view that from the reproductions printed it is not possible to make this claim. It would appear that the first radiograph shows multiple metastases in both lung fields with what appear to be bilateral basal effusions and a large area of consolidation adjacent to the right heart border. In the second reproduction, after treatment, the effusions have cleared and there is a reduction in size of the "consolidated area" near the right hilum, but this resolution is not complete. The multiple metastases are still present though they do not coincide exactly with those on the first film.

It would seem that while there has been considerable improvement with treatment the caption indicating "complete regression of a pulmonary metastasis" is misleading.-We are, etc.,

$X$-ray Department,

A. W. O'MALley

Hospital Centre,

Department of Radiodiagnosis,
University Hospital of Wales,

Michael SHAW Univers

\section{Tests of Acupuncture}

SIR,-As a means to prevent pain in surgery I have no doubt that acupuncture worksBut (with a capital B) only in a limited range of surgery, and in a very, very limited number of patients; and in this respect it differs not at all from hypnotism, mesmerism, suggestion, animal magnetism, call it what you will. The idea that acupuncture can be grouped with general anaesthetics and local analgesics, or that currently it "is em- ployed for most of the major surgery that is undertaken on the Chinese mainland nowadays" (Dr. P. E. Brown 30 June, p. 780) is, in my opinion, nonsense.

At the suggestion of Mr. J. S. Horn, F.R.C.S., I had the good fortune to be invited by the Chinese Medical Association and spent eight weeks in the autumn of 1959 on an anaesthetics lecture/demonstration tour in that country. I travelled extensively, visiting Peking, Changchun, Shenyang (Mukden), Anshan, Sian, Chungking, Wuhan, Shanghai, Hangchow, and Canton. I had with me a dictating machine of which my hosts approved, and which indeed on one occasion they repaired though they were unfamiliar with it. I made on-the-spot notes and dictated freely from these on my return to the hotel. Transcription of the dictation belts was made in England as the result of which I have a diary of 430 typewritten quarto pages. I had the advantage of having the same personal interpreter throughout, Dr. Shang, senior anaesthetist at the Peking Chest Hospital who had in 1948-9 spent 12 months with an internationally known anaesthetist in mid-America. He proved helpful, pleasant, and well informed. I received the most courteous and considerate treatment everywhere and came away, like every other visitor I have heard of, enormously impressed by what had been accomplished in that great country. This visit of mine changed most of my preconceived ideas about China, but not about acupuncture, of which, at my request, I saw quite a lot, and made full notes.

In brief, I saw nothing done under acupuncture more remarkable than the surgery described and illustrated in the book by Esdaile ${ }^{1}$ published in 1846, just before the introduction of ether.

All these operations were carried out with the help only of mesmerism. I could cite many other contemporary references. A quite recent article in Anaesthesia, the official journal of the Association of Anaesthetists, was entitled "Surgery under Hypnosis." In this we read that in Britain two impacted wisdom teeth requiring incision of gum and use of bone chisels "were removed completely painlessly under hypnosis." Also in the same patient, but on a different occasion, a bilateral mammaplasty was successfully carried out under hypnosis. At one point the patient "remarked that she was thirsty and was given a drink with a feeding cup while the operation continued." During surgery under acupuncture munching orange segments is currently more favoured. ${ }^{35}$ It is noteworthy that the above article excited no comment. Were the procedures to be repeated now, with benefit of acupuncture, I have little doubt they would hit the headlines both lay and medical.

In China I formed the impression that specific acupuncture points, at any rate those unrelated of gross anatomy, were phoney, and that the same results, good and disappointing, would have followed had the needles been inserted elsewhere. And I have no doubt that my views were shared by my Chinese colleagues who had received an orthodox ("Western" to them) medical training. But my colleagues were loyalists. They were not concerned whether the procedure was well founded scientifically; what mattered was whether it was good for their country. The more I learnt about the recent history 